\title{
Moroccan Cedar softwood study: Application of FT-Raman spectroscopy
}

\author{
Somia Fellak ${ }^{1, \mathrm{a}}$ and Abdellatif Boukir ${ }^{1}$ \\ ${ }^{1}$ Department of Chemistry, Faculty of Sciences and Techniques at Fez, SMBA University, Fez, Morocco
}

\begin{abstract}
As non-destructive technique, FT-Raman spectroscopy has been used to study the molecular structure and monitor changes in the composition of carbohydrates and lignin components containing wood materials. For this purpose, four samples originated from Moroccan cedar wood were analyzed. Following the FT-Raman spectra, it was found that carbohydrates were identified by the bands at $898,1098,1123$ and $1456 \mathrm{~cm}^{-1}$, while lignin matrix was evaluated by the bands at 1657,1598 and $1267 \mathrm{~cm}^{-1}$. The decrease of the intensities related to these feature bands reflects the effects of natural degradation phenomenon and shows the evidence of chemical changes and quick deterioration of these contents upon exposure time to natural degradation process. Thus, the FT-Raman tool has the potential to be one of crucial sources to characterize composite materials and to evaluate the chemical changes occurred on their structures under the influence of physico-chemical or biological attacks without causing any damage of the wood surfaces or their supports.
\end{abstract}

\section{Introduction}

Moroccan softwood, as one of the most abundant materials on earth, is provides a resource of great value for construction and production of novel objects since antiquity. It is extensively used for many applications (artworks, packaging industry, shipbuilding, furniture, paper pulp, eating utensils, etc) since antiquity.

These materials have a heterogeneous and complex structure, primarily consisting of cellulose, lignin and hemicelluloses components which are reported as one group of materials with a well-known reputation for susceptibility to natural deterioration. The exposition to combined conditions of physical, chemical and microbial attack as ultraviolet (UV) light, solar irradiation, moisture (humidity), temperature and fungus can cause molecular degradation of their main components. It results a loss of fiber strength and rigidity. This is manifested in lower mechanical stability that may leads, sometimes, to full disintegration of wooden materials [1], and consequently results in loss of cultural heritage [2].

Hence, an accurate characterization and examination of different changes occurred in these materials through a spectroscopic study by non-destructive techniques, is extremely important for optimal safeguarding and preservation.

A very few works have been conducted on structural characterization and/or structural degradation of wood by Fourier transform Raman spectroscopy (FT-Raman) [3-6], in contrast to the other spectroscopic techniques which are the most used for material's study as Fouriertransform infrared spectroscopy (FTIR), X-ray diffraction (XRD), scanning electron microscopy (SEM) and nuclear magnetic resonance (NMR). In this field, Agarwal and Ralph [3] have applied FT-Raman technique to identify the major constituents of black spruce wood: lignin, cellulose and hemicelluloses, while Ona et al. [7] have performed interesting researches on the Eucalyptus wood properties by the same technique.

Recently, FT-Raman is being more performed for the chemical analysis of biomaterials as wood [8-9]. It provides more information about polymer chain and fundamental knowledge at a molecular (micro-level) and macro-level [10]. In addition, it has been shown to be a valuable technique for analyzing structural changes in the fibers which arise from physical, chemical or mechanical processing [11-12]. Hence it is possible to perform fast, non destructive and non invasive measurements without extensive sample preparation [9].

As this non-destructive spectroscopic method seems to be a promising instrument for studying composition of wood materials, the main goal of the present work is to investigate, in details, the distribution of chemical composition in softwood materials and understand the structural rearrangement caused by the effect of natural degradation process.

\footnotetext{
${ }^{\mathrm{a}}$ Corresponding author: soumaya.fellak@gmail.com
} 


\section{Materials and methods}

\subsection{Sampling}

Analyzed Softwood samples were collected from four archaeological Cedar wood (Cedrus atlantica) dating to the $18^{\text {th }}, 19^{\text {th }}, 20^{\text {th }}$ and $21^{\text {st }}$ centuries in the Ecomuseum of Tazekka under standard climate. The pieces originate from Tazekka national park (WGS84: $34^{\circ} 6^{\prime} 0^{\prime \prime} \mathrm{N}$, $\left.4^{\circ} 11^{\prime} 0^{\prime \prime} \mathrm{W}\right)$ located in the Middle Atlas of Morocco and near the city of Taza (Bab Boudir region). The samples were dated by specialist researchers using Radiocarbon dating method. Thus, the dimensions of wood samples are $200 \times 200 \times 100 \mathrm{~mm}^{3}$ (tangential $\times$ radial $\times$ longitudinal directions). The characteristics of the experimental materials are presented in Table 1. The FT-Raman analysis was performed directly on the surface of the samples.

Table 1. Sample's description.

\begin{tabular}{|c|c|}
\hline Sample & Age (century) \\
\hline $\mathrm{D}_{1}$ & $21^{\text {th }}$ \\
\hline $\mathrm{D}_{2}$ & $20^{\text {th }}$ \\
\hline $\mathrm{D}_{3}$ & $19^{\text {th }}$ \\
\hline $\mathrm{D}_{4}$ & $18^{\text {th }}$ \\
\hline
\end{tabular}

\subsection{FT-Raman spectroscopy}

The FT-Raman study was conducted with a Bruker (USA) MultiRAM Stand Alone FT-Raman Spectrometer. The instrument is equipped with a diodepumped Nd:YAG excitation source with a large emission intensity at $1.064 \mathrm{~nm}$. Furthermore, the signal was collected with a liquid nitrogen cooled germanium detector. For each FT-Raman measurement 100 scans were averaged, with a resolution of $4 \mathrm{~cm}^{-1}$ and a time measurement of $3 \mathrm{~min}$ for each spectrum. All FTRaman spectra were registered from 4000 to $250 \mathrm{~cm}^{-1}$. Three analyses were performed on several locations for each sample. The temperature and humidity room were controlled during analysis.

\section{Experimental results}

The common bands assignments of four wood's sample $\left(D_{1}, D_{2}, D_{3}\right.$ and $\left.D_{4}\right)$, are given in Table 2. The band's attribution was extremely difficult due to the overlapping of some cellulose and lignin bands; and so, it confirmation was based on different literature data $[5$, 6 , 13] which focused on the wood study and investigation of degradation effect using FT-Raman spectroscopy.
Table 2. Assignment of characteristic FT-Raman bands of softwood materials $\left(\mathrm{D}_{1}, \mathrm{D}_{2}, \mathrm{D}_{3}\right.$ and $\left.\mathrm{D}_{4}\right)$ [13-21].

\begin{tabular}{|c|c|}
\hline $\begin{array}{l}\text { Wavenumber } \\
\qquad\left(\mathrm{cm}^{-1}\right)\end{array}$ & Assignment \\
\hline 2943 & $\square \mathrm{CH}$ (asymmetric) in $\mathrm{OCH}_{3}$ of lignin \\
\hline 2895 & $\begin{array}{l}\mathrm{CH}_{2} \text { group in the glucopyranose ring } \\
\text { of cellulose } \mathrm{I}_{\beta}\end{array}$ \\
\hline 1657 & $\begin{array}{l}\text { Conjugated } \mathrm{C}=\mathrm{C} \text { stretching of } \\
\text { coniferyl alcohol (guaiacyl) in lignin } \\
\text { that overlaps with } \mathrm{C}=\mathrm{O} \text { stretch of } \\
\text { coniferyl aldehyde }\end{array}$ \\
\hline 1598 & $\begin{array}{l}\square \mathrm{C}=\mathrm{C} \text { aromatic skeletal vibration } \\
\text { typical for lignin guaiacyl and } \\
\text { syringyl monomer in lignin }\end{array}$ \\
\hline 1456 & $\begin{array}{l}\text { HCH bending and small proportion of } \\
\text { HOC bending in pure or amorphous } \\
\text { cellulose }\end{array}$ \\
\hline 1378 & $\begin{array}{l}\delta(\mathrm{C}-\mathrm{H}) \text { and } \delta\left(\mathrm{CH}_{2}\right) \text { in cellulose and } \\
\text { hemicelluloses }\end{array}$ \\
\hline 1333 & $\begin{array}{l}\mathrm{C}-\mathrm{H} \text { vibration in cellulose and } \mathrm{C}-\mathrm{O} \\
\text { vibration in syringyl derivatives }\end{array}$ \\
\hline 1267 & $\begin{array}{l}\mathrm{C}_{\mathrm{ar}}-\mathrm{O} \text { of aryl-O- } \mathrm{CH}_{3} \text { and/or aryl-OH } \\
\text { of guaiacyl/syringyl monomer } \\
\text { aromatic ring }\end{array}$ \\
\hline 1123 & \multirow{2}{*}{$\begin{array}{l}\text { Stretching vibration of C-O, C-O-C } \\
\text { glycosidic linkage in cellulose and } \\
\text { xylan or C-C ring }\end{array}$} \\
\hline 1092 & \\
\hline 898 & $\begin{array}{l}\text { CH deformation in amorphous } \\
\text { cellulose }\end{array}$ \\
\hline 379 & $\delta_{\mathrm{s}}(\mathrm{CCC})$ in crystalline cellulose \\
\hline
\end{tabular}

Figure 1 reports the representative FT-Raman spectra for each sample $\left(D_{1}, D_{2}, D_{3}\right.$ and $\left.D_{4}\right)$ between the spectral region of $3500-500 \mathrm{~cm}^{-1}$.

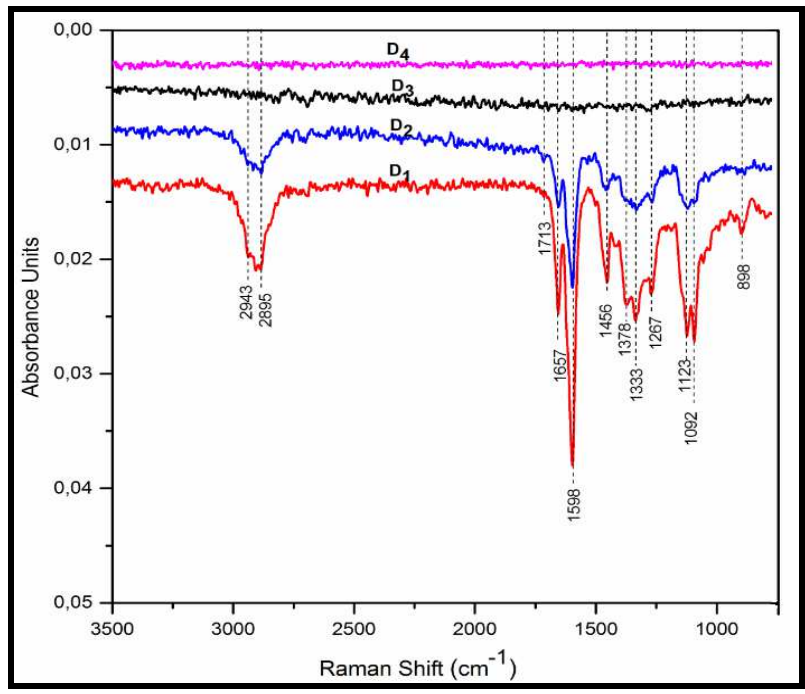

Figure 1. FT-Raman spectra acquired from the four samples of softwood: $\mathrm{D}_{1^{-}}$Wood sample dating to $21^{\text {st }}$ century; $\mathrm{D}_{2}$ Wood sample dating to $20^{\text {th }}$ century; $\mathrm{D}_{3^{-}}$- Wood sample dating to $19^{\text {th }}$ century; $\mathrm{D}_{4^{-}}$Wood sample dating to $18^{\text {th }}$ century.

\subsection{Cellulose and hemicelluloses}

The main characteristic FT-Raman signals for cellulosic and hemicellulosic fibers can be visually divided into 
two essential regions: $3500-2800 \mathrm{~cm}^{-1}$ and $1480-250$ $\mathrm{cm}^{-1}$ fingerprint region (Fig. 1 and 2).

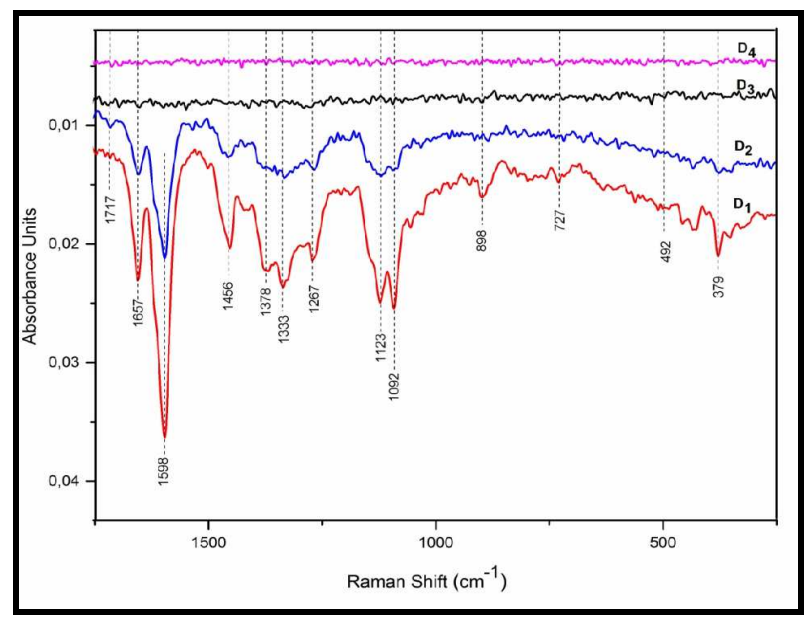

Figure 2. FT-Raman spectra $1750-250 \mathrm{~cm}^{-1}$ range acquired from the four samples of softwood: $\mathrm{D}_{1^{-}}$- Wood sample dating to $21^{\text {st }}$ century; $\mathrm{D}_{2}$ - Wood sample dating to $20^{\text {th }}$ century; $\mathrm{D}_{3}$ Wood sample dating to $19^{\text {th }}$ century; $\mathrm{D}_{4}$ - Wood sample dating to $18^{\text {th }}$ century.

For the first region, the detected bands are mainly due to the hydroxyl groups, methyl and methylene stretching vibrations. Concerning the second range, the bands correspond to methylene, methyl bending, wagging, rocking, C-O-H in-plane bending and $\mathrm{C}-\mathrm{O}-\mathrm{H}$ in-plane bending and skeletal bending vibrations (CCC, COC, OCC and OCO). Thus, the deterioration of the cellulose and hemicelluloses fractions has been explained by the decline in intensities of these bands (Fig. 1) during exposure to natural atmospheric effect.

The recent samples dating to $21^{\text {st }}$ and $20^{\text {th }}$ century (Fig. 1. $\mathrm{D}_{1}$ and $\mathrm{D}_{2}$ ) clearly display a feature band at $2895 \mathrm{~cm}^{-1}$. According to Barnette et al. [13], the latter was attributed to symmetric stretching vibrations of the $\mathrm{CH}_{2}$ group in the glucopyranose ring of cellulose $\mathrm{I}_{\beta}$. The presence of this band in spectra of $\mathrm{D}_{3}$ and $\mathrm{D}_{4}$ (Fig. 2) degraded samples dating to $19^{\text {th }}$ and $18^{\text {th }}$ century respectively, suggests that upon a long exposure to the degradation phenomenon, the crystalline fraction decomposes and results disorder fraction which in turn re-crystallized and formed the new ordered fraction. This finding can be confirmed by the decline in intensities of feature bands typical of amorphous cellulose at $1456 \mathrm{~cm}^{-1}$ and $898 \mathrm{~cm}^{-1}$ and assigned to $\mathrm{HCH}$ bending and small proportion of $\mathrm{HOC}$ bending in amorphous cellulose as well as $\mathrm{CH}$ deformation in amorphous cellulose, respectively [14]. On the other hand, the $\mathrm{C}-\mathrm{H}$ and $\mathrm{CH}_{2}$ deformations in cellulose and hemicelluloses compounds were observed at $1378 \mathrm{~cm}^{-1}$.

From spectra of sample $\mathrm{D}_{1}$ and $\mathrm{D}_{2}\left(1200-1000 \mathrm{~cm}^{-1}\right)$, it is easily to distinguish a doublet of peaks at 1123 and $1092 \mathrm{~cm}^{-1}$ assigned to combined stretching vibration of $\mathrm{C}-\mathrm{O}$ ring and $\mathrm{C}-\mathrm{O}-\mathrm{C}$ glycosidic linkages in cellulose and hemicellulose $[13,15]$; providing information about the breaking of cellulosic chains at the $\beta$-1,4-glycosidic ether bonds. Thus, the disappearance of these two bands in spectra of oldest samples (Fig. $2 \mathrm{D}_{3}$ and $\mathrm{D}_{4}$ ) indicates the serious degradation occurred on cellulose and hemicelluloses.

Referring to literature data [16], the bands at 379 $\mathrm{cm}^{-1}$ can be unambiguously attributed to CCC deformations in crystalline fraction of cellulose. Fig. 2 shows a discernible decrease of this band proportionally with the age of sample, indicating the loss in mechanical rigidity and toughness for these materials, consequently, the surrender of lignocellulosic biomass against deconstructive processes.

The weak features at 379 and $440 \mathrm{~cm}^{-1}$ might be explained as a result of intermolecular interactions between lignin and carbohydrates, that can caused a small shifts in peak positions and/or changes in band shapes [3].

\subsection{Lignin}

In order to estimate lignin fraction, different bands were studied. In the region between $3100-2800 \mathrm{~cm}^{-1}$, the band at $2943 \mathrm{~cm}^{-1}$ was attributed to the $\mathrm{C}-\mathrm{H}$ stretching of the methoxy groups in lignin [5, 6]. It appears less pronounced in the oldest samples dating to the $19^{\text {th }}$ and $18^{\text {th }}$ centuries (Fig. $1 \mathrm{D}_{3}$ and $\mathrm{D}_{4}$ ) indicating lower lignin presence compared to the youngest ones (Fig. $1 \mathrm{D}_{1}$ and $\mathrm{D}_{2}$ ).

The detection of feature band at $1717 \mathrm{~cm}^{-1}$ in spectra of samples $\mathrm{D}_{2}, \mathrm{D}_{3}$ and $\mathrm{D}_{4}$ (Fig. 2) indicates the presence of carbonyl groups related to the residual lignin amount resulted from delignification of wood sample upon process of natural degradation. It relative intensity appears no changeable for all oldest samples, while it appears absent in $\mathrm{D}_{1}$ spectrum (Fig. 2). The non important sensitivity of this produced amount to degradation events is the possible explanation in this case.

Furthermore, the combined band in the region between 1657 and $1598 \mathrm{~cm}^{-1}$ was mainly originates from guaiacyl (coniferyl alcohol units for softwood) and syringyl (sinapyl alcohols units for hardwood) matrix in lignin compound. The band detected at $1657 \mathrm{~cm}^{\square-\square 1}$ is attributed to conjugated $\mathrm{C}=\mathrm{C}$ stretching vibration of coniferyl alcohol (guaiacyl) in lignin that overlaps with $\mathrm{C}=\mathrm{O}$ stretch of coniferyl acid after oxidation of alcohol in side chain [6, 17]. According to Kihara et al. [18], this band can also assigned to marker bands for conjugate carbonyl groups $(\alpha, \beta$-unsaturated $\mathrm{C}=\mathrm{O})$.

The most intense peak at $1598 \mathrm{~cm}^{-1}$ (Fig. $2 \mathrm{D}_{1}$ and $\mathrm{D}_{2}$ ) is attributed to stretching vibration of polar aromatic $\mathrm{C}=\mathrm{C}$ in phenolic compounds [19] related to guaiacyl and syringyl monomers in lignin $[5,20]$.

The other predominant lignin band was detected at $1267 \mathrm{~cm}^{-1}$ and corresponds to $\mathrm{C}_{\text {aromatic }}-\mathrm{O}$ of guaiacyl lignin for softwood [17]. It shifted to lower intensities during exposure time to natural degradation process (Fig. 2), because of guaiacyl lignin is less susceptible than syringyl lignin. Nevertheless, for hardwood spectra, there is a rapid decline in its intensity. Thus, we can confirm that our cedar samples belong to the softwood specie. 
It is likely reported that decomposition of hemicelluloses and/or extractives, can lead to the decrease in quantity of lignin, consequently, a simultaneous deterioration of wooden materials.

\section{Conclusions}

The present work has put in evidence the crucial role of FT-Raman spectroscopy as non destructive method to characterize and study the effect of natural degradation on chemical structure of cellulose, hemicelluloses and lignin as major components of softwood by providing accurate information about their chemical structures. Based on the obtained results, the gradual decline in intensities of features bands related to these constituents for each compound of wood, suggest their sensitivity to combined degradation agents and, consequently, irreversible losses of softwood material in archaeological sites.

The authors gratefully acknowledge technical support by National Center for Scientific and Technical Research in Morocco. We thank the Ministry of Culture, Arts and Museum Division for sampling step.

\section{References}

1. E. Marengo, E. Robotti, M. C. Liparota, M. C. Gennaro, Talanta 63 (2004)

2. T. Rosado, M. Silva, C. Pereira, J. Mirão, A. Candeias, A. Teresa Caldeira, I. J. C. S. 6 (2015)

3. U. P. Agarwal, S.A. Ralph, Appl. Spectrosc. 51 (1997)

4. Y. Xia, T.Y. Chen, J.L. Wen, Y. Zhao, J. Qiu, R.C. Sun, Int. J. Biol. Macromol. 109 (2018)

5. Z. Ji, J.F. Ma, Z.H. Zhang, F. Xu, R.C. Sun, Ind. Crop. Prod. 47 (2013)

6. Ö. Ozgens, S. Durmaz, I.H. Boyaci, H. EksiKocak, Spectrochim. Acta A. 171 (2017)

7. T. Ona, T. Sonoda, K. Ito, M. Shibata, T. Kato, Y. Ootake, Y. Tamal, Y. Kojima, J. Pulp Pap. Sci. 26 (2000)

8. M.R. Almeida, C.H.V Fidelis, L.E.S. Barata, R.J. Poppi, Talanta 117 (2013)

9. V. Emmanuel, B. Odile, R. Céline, Spectrochim. Acta Part A Mol. Biomol. Spectrosc. 136 (2015)

10. U.P. Agarwal, An Overview of Raman Spectroscopy as Applied to Lignocellulosic Materials (Advances in Lignocellulosics Characterization, Paper Industry Management Association, TAPPI Press, Atlanta, USA, 1999)

11. H. Edwards, D. Farwell, D. Webster, Spectrochim. Acta A. 53 (1997)

12. A.P.P. Alves, L.P.Z. de Oliveira, A.A.N. Castro, R. Neumann, L.F.C. de Oliveira, H.G.M. Edwards, A.C. Sant'Ana, Vib. Spectrosc. 86 (2016)
13. A.L. Barnette, C. Lee, L.C. Bradley, E.P. Schreiner, Y.B. Park, H. Shin, D.J. Cosgrove, S. Park, S.H. Kim, Carbohyd. Polym. 89 (2012)

14. S.A. Centeno, A.Vila, L. Barro, Microchem. J. 114 (2014)

15. S. Yamauchi, Y. Iijima, S. Doi, J. Wood. Sci. 51 (2005)

16. M. Zhang, C. Lapierre, N.L. Nouxman, M.K. Nieuwoudt, B.G. Smith, R.R. Chavan, B.H. McArdle, P.J. Harris, Plant. Physiol. Bioch. 118 (2017)

17. A. Cogulet, P. Blanchet, V. Landry, J. Photochem Photobiol B. 158 (2016)

18. M. Kihara, M. Takayama, H. Wariishi, H. Tanaka, Spectrochim. Acta A. 58 (2002)

19. A. Boukir, M. Guiliano, L. Asia, G. Mille, Analusis. 26 (1998)

20. S. Yamauchi, Y. Tamura, Y. Kurimoto, A. Koizumi, J. Adhes. Soc. Jpn. 33 (1997)

21. B. Zghari, P. Doumenq, A. Roman, A. Boukir, J. Mater. Environ. Sci. 8 (2017) 